\title{
Comparison of Fenoterol, Isoproterenol, and Isoetharine with Phenylephrine Aerosol in Asthma
}

\author{
GeORGE G. SPELlMAN, JR., M.D.," BARBARA J. GRUEBEL, M.D., \\ JOEL D. EPSTEIN, M.D., HAROLD H. ROTMAN, M.D., and \\ JOHN G. WEG, M.D. Ann Arbor, Mich.
}

\begin{abstract}
The bronchodilator effect of fenoterol hydrobromide $(0.5,1.25$, and $2.5 \mathrm{mg})$ was compared with either isoproternol $(2.8 \mathrm{mg})$ or isoetharine $(5 \mathrm{mg})$ with phenylephrine $(1.25 \mathrm{mg})$ in a double-blind placebo-controlled study. When delivered by an intermittent positive-pressure breathing device to 24 nonsmoking young adult asthmatic subjects, fenoterol produced significant improvement in forced expiratory volume at 1 second $\left(F E V_{1}\right)$, in maximum midexpiratory flow ( $\left.F E F_{25-75 \%}\right)$, and in forced expiratory flow at 25 per cent of vital capacity $\left(F E F_{25 \%}\right.$ ) for 6 to 8 hours, whereas isoproterenol and isoetharine with phenylephrine produced improvement for 1 and 2 hours, respectively. The lowest dosage of fenoterol was as effective as the highest but had fewer adverse effects.
\end{abstract}

$F_{d}$ JeNOTERol hydrobromide, (1-3,5-dihydroxyphenyl)-1-hydroxy-2-(4-hydroxyphenylisopropylamino)ethane (TH 1165a), structurally related to metaproterenol, is a relatively selective $\beta_{2}$-adrenergic agonist with a prolonged duration of action. ${ }^{1-5}$ The purpose of this study was to compare fenoterol in three different doses with isoproterenol, isoetharine combined with phenylephrine, and a placebo, all delivered with an intermittent positive-pressure breathing (IPPB) device to young adults with uncomplicated asthma.

\section{Methods}

Twenty-four informed volunteer participants (14 female and 10 male) had asthma characterized by episodic shortness of breath

From the Pulmonary Division, Department of Medicine, University of Michigan Medical School, Ann Arbor, Mich. 48109. Supported in part by a grant from Boehringer-Ingelheim, Ltd., Elmsford, N.Y.

* Current addres8: 6699 Alvarado Road, Suite 2308, San Diego, Calif. 92120 and wheezing brought on by various stimuli which changed in severity spontaneously and with therapy. They were 18 to 30 years old (average 22 years) and had had asthma an average of 17 years (range 1 to 30 years). Historically, 23 had reactions to identified allergens; 21 had hayfever, eczema, and/or hives; and 22 had family members with atopic disorders. Of the 21 who had been skin tested, all gave histories of positive immediate reactions. Nineteen had greater than 5 per cent eosinophils in their peripheral blood. Twenty-one were nonsmokers, while three had minimal past smoking histories ( 0.14 pack years having stopped three years ago, 0.12 pack years having stopped eight years ago, and 3.8 pack years having stopped seven years ago). None had chronic bronchitis or other respiratory diseases.

In order to participate, the subjects had to achieve a 20 per cent improvement in their forced expiratory volume at 1 second $\left(F E V_{1}\right)$

The Journal of Clinical Pharmacology 


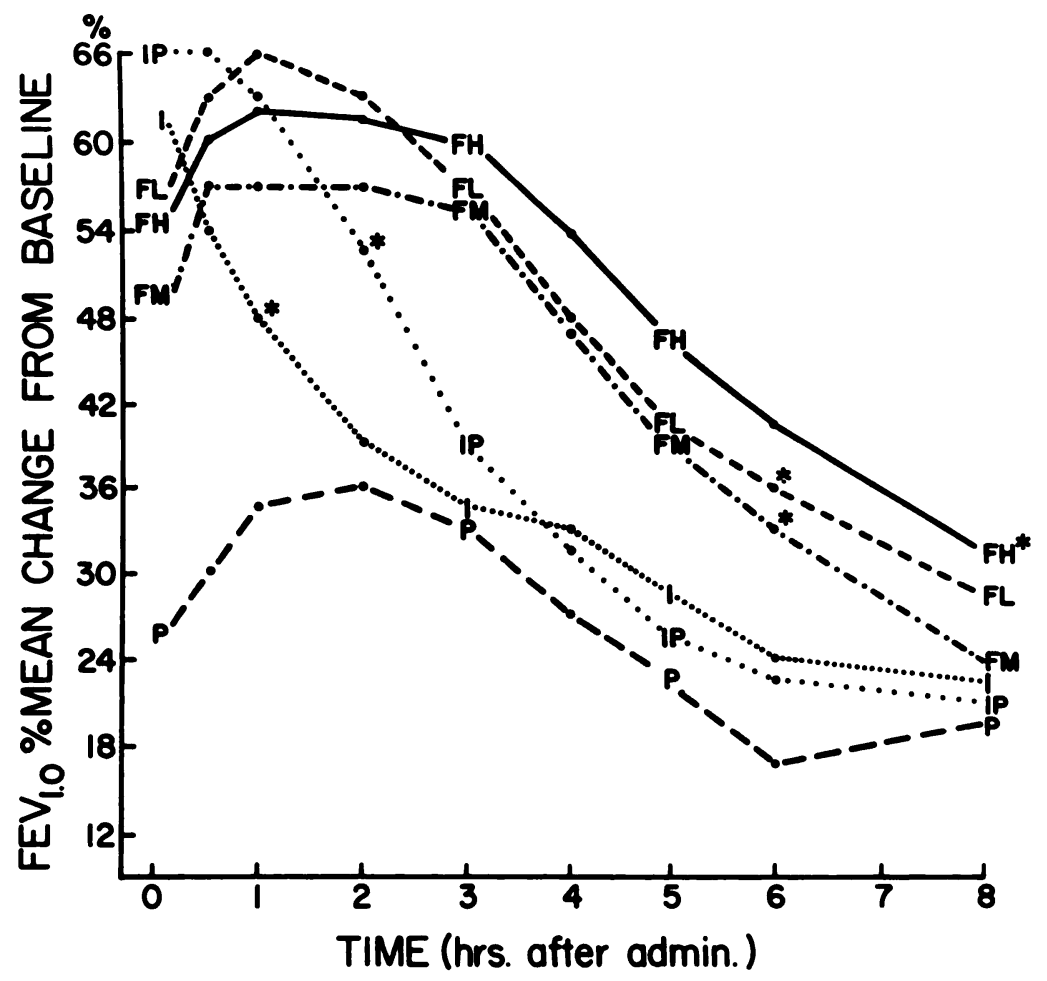

Fig. 1. Per cent mean change from baseline of $F E V_{1}$ following administration of placebo (--P--); isoproterenol $2.8 \mathrm{mg}(\cdots . \cdots)$; isoetharine $5 \mathrm{mg}$ with phenylephrine $1.25 \mathrm{mg}(\cdot \cdot \mathrm{IP} \cdot \cdot)$; fenoterol $0.5 \mathrm{mg}(\cdot-\mathrm{FL} \cdot-), 1.25 \mathrm{mg}(-\cdot F M-\cdot)$, or $2.5 \mathrm{mg}(-\mathrm{FH}-)$. * Duration for which change from baseline of the treatment group is significantly greater than the change from baseline of the placebo group.

within 30 minutes of receiving $0.15 \mathrm{mg}$ isoproterenol by metered dose inhaler. They were then excluded if their $\mathrm{FEV}_{1}$ was greater than 70 per cent of predicted or if they had cardiac, renal, hepatic, endocrine, or metabolic disease. Abnormalities of screening CBC with differential, blood sugar, BUN, SGOT, total bilirubin, total protein, albumin, or electrocardiogram also led to exclusion. Complete physical exam and history were performed prior to study. The evaluation was repeated at the completion of testing.

Studies were done the same time each day but at least 24 hours apart. No long-acting bronchodilators were taken for 12 hours, and no other bronchodilators or cromolyn sodium were taken for $\mathbf{8}$ hours prior to or during testing. A stable dose of beclomethasone was continued throughout the study in three subjects, but otherwise no patient was receiving corticosteroids.

Spirometry and flow-volume loops were done in triplicate to obtain the forced expiratory volume at 1 second $\left(F E V_{1}\right)$, forced vital capacity (FVC), maximum midexpiratory flow (FEF $25-75 \%)$, and forced expiratory flow at 25 per cent of vital capacity (FEF $25 \%)$. The measurements from the test giving the best $\mathrm{FEV}_{1}$ were used. On test days, if the $F_{1} V_{1}$ was less than 70 per cent of predicted, testing was continued and spirometry, flow-volume loops, blood pressure, and pulse measurements were done at baseline and at 5 and 30 minutes and $1,2,3,4,5,6$, and 8 hours after drug administration. An 
electrocardiogram was taken at baseline and at 30 minutes. Testing was discontinued prior to 8 hours if the subject was symptomatic and the $\mathrm{FEV}_{1}$ had returned to baseline. During the testing, the patients were specifically questioned about symptoms of nervousness, trembling, palpitation, vertigo, and headache. Patients did quiet activities during the studies.

Isotonic saline (placebo), fenoterol hydrobromide $(0.5,1.25$, and $2.5 \mathrm{mg})$, isoproterenol hydrochloride $(2.8 \mathrm{mg})$, or a combination of isoetharine hydrochloride $(5 \mathrm{mg})$ with phenylephrine hydrochloride (1.25 $\mathrm{mg}$ ) in normal saline was administered in random order (table of random numbers) with the Porta-Bird (Bird Corp., Palm Springs, Calif.) IPPB machine using air at a setting of $15 \mathrm{~cm} \mathrm{H}_{2} \mathrm{O}$. Niether the subjects nor the physicians administering the pulmonary function tests knew the identity of the drug on a test day.

Pulmonary functions were performed with a rolling seal spirometer (Model 220), a Pulmo-Norm Digitizer (Model 560), and an $\mathrm{X}-\mathrm{Y}$ recorder (Model 750) produced by Cardio-Pulmonary Instruments Corp., Houston, Tex.

Statistical analysis of results was carried out with comparison between paired variables made with the $t$-test (significance level 0.05) and multiple comparisons among var-

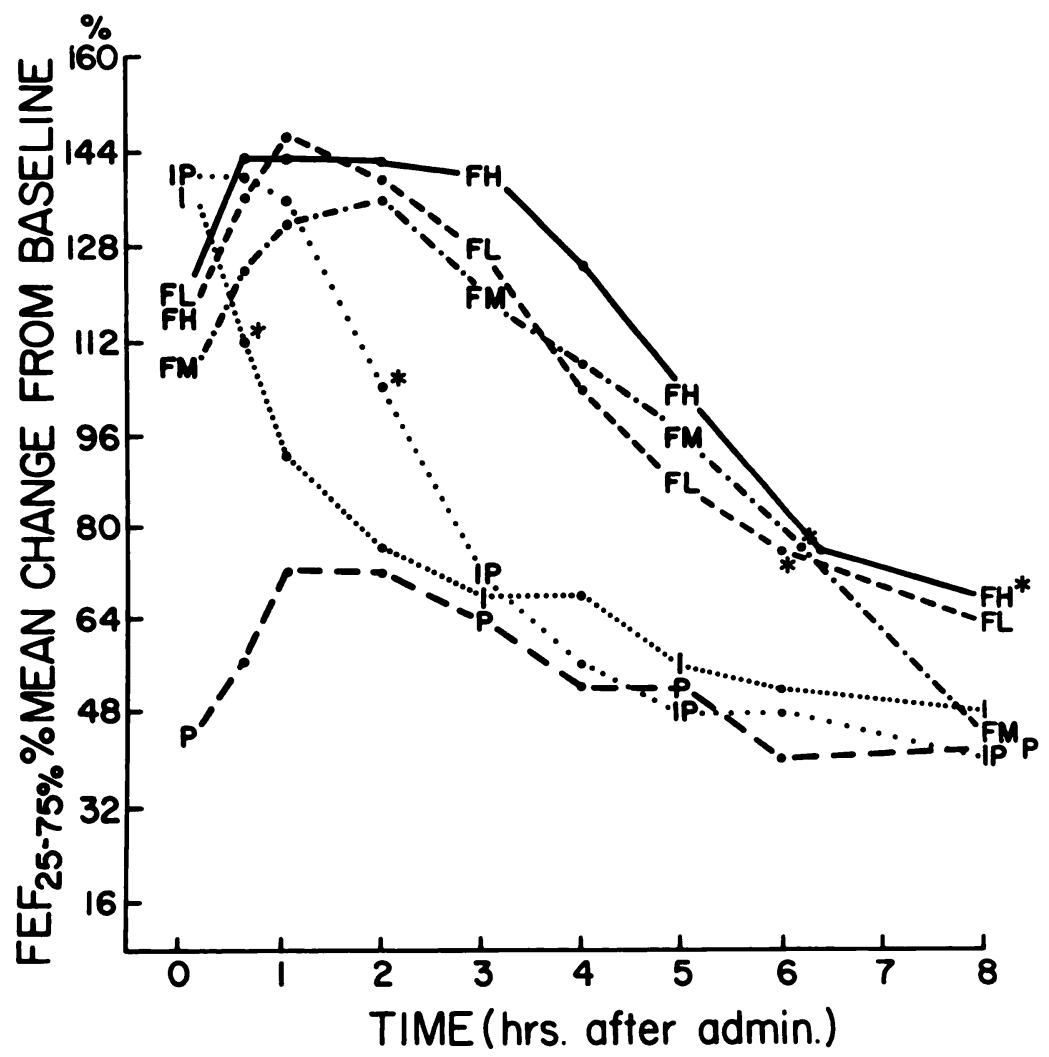

Fig. 2. Per cent mean change from baseline of $F E F_{25-75 \%}$ following administration of placebo (--P--); isoproterenol $2.8 \mathrm{mg}$ (……); isoetharine $5 \mathrm{mg}$ with phenylephrine $1.25 \mathrm{mg}(\cdot \cdot \mathrm{IP} \cdot \cdot)$; fenoterol $0.5 \mathrm{mg}(-F L-), 1.25 \mathrm{mg}(-\cdot F M-\cdot)$ or $2.5 \mathrm{mg}(-\mathrm{FH}-)$. ${ }^{*}$ Duration for which change from baseline of the treatment group is significantly greater than the change from baseline of the placebo group. 


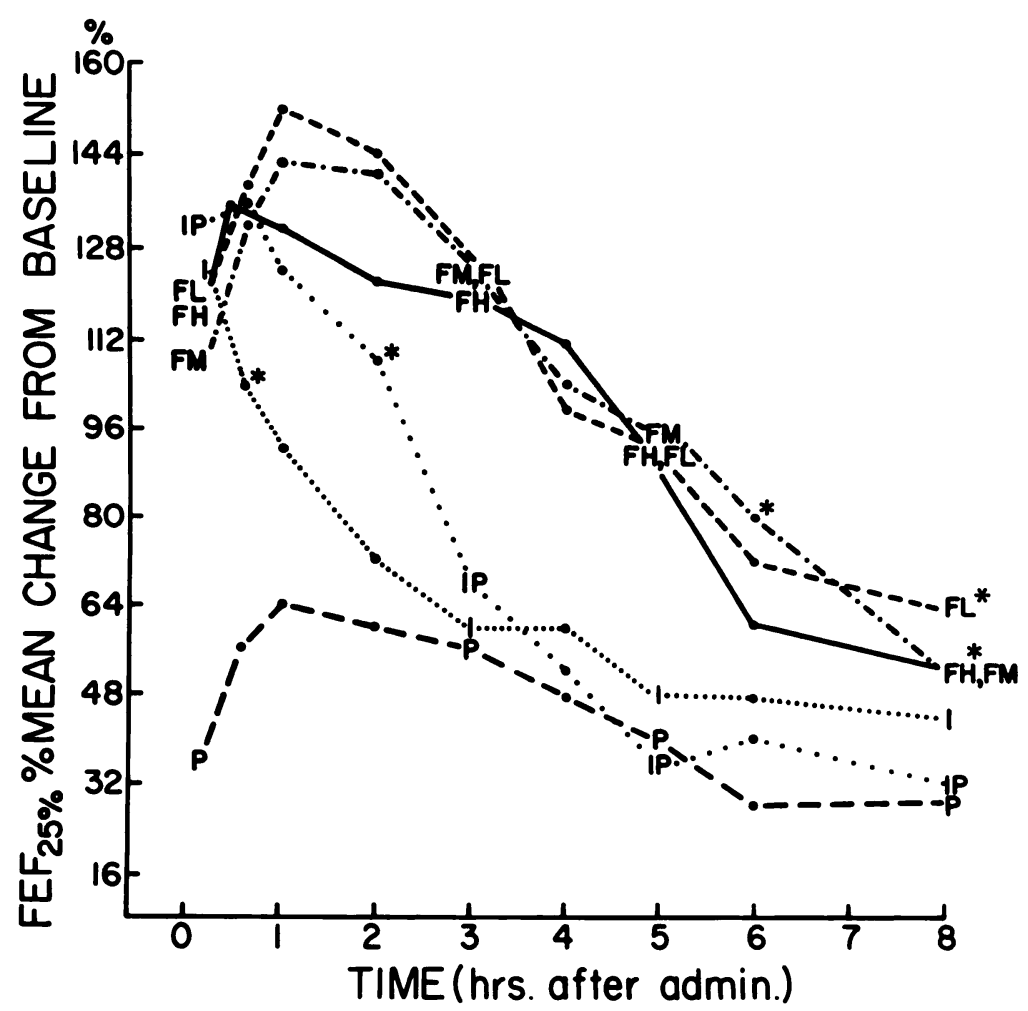

Fig. 3. Per cent mean change from baseline of $F E F_{25}{ }_{1}$ following administration of placebo (--P--); isoproterenol $2.8 \mathrm{mg}$ (... $\cdots$ ); isoetharine $1.25 \mathrm{mg}$ (- IP. -); fenoterol $0.5 \mathrm{mg}(-\cdot F L--), 1.25 \mathrm{mg}(-\cdot F M-\cdot)$, or $2.5 \mathrm{mg}(-F H-)$. * Duration for which change from baseline of the treatment group is significantly greater than the change from baseline of the placebo group.

iables made with Duncan's multiple range test (significance level 0.05).

The study design was approved by the Committee to Review Grants for Clinical Research and Investigation Involving $\mathrm{Hu}$ man Beings of the University of Michigan Medical School. Further information from the Food and Drug Administration relating to the increased incidence of "tumors" in rats receiving albuterol was given to the participants when it became available during the study, and those who had not completed the study were required to give this additional consent before continuing.

\section{Results}

Testing was discontinued in 20 instances (four with placebo, four with isoetharine with phenylephrine, three with isoprote- renol, and two with each dose of fenoterol) because the subjects were symptomatic and the $\mathrm{FEV}_{1}$ had returned to baseline.

There was no significant difference in

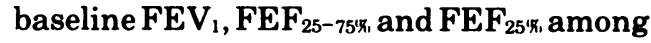
treatment groups. Percentage mean changes in $\mathrm{FEV}_{1}, \mathrm{FEF}_{25-75 \%, \text { and }} \mathrm{FEF}_{25}$, are shown in Figs. 1 to 3, and Table I. Fenoterol had a longer duration of action than either isoproterenol or isoetharine with phenylephrine. The mean changes from baselines in FEV 1 and $\mathrm{FEF}_{25}$, of the three fenoterol treatment groups were not different at 8 hours. The mean changes from baselines in $\mathrm{FEF}_{25-75}$, of the three fenoterol treatment groups were not different at 6 hours. But at 8 hours, the mean change in $\mathrm{FEF}_{25-75 \%}$, was greater for the 2.5 -mg fenoterol treatment group than for the 1.25-mg fenoterol treat- 


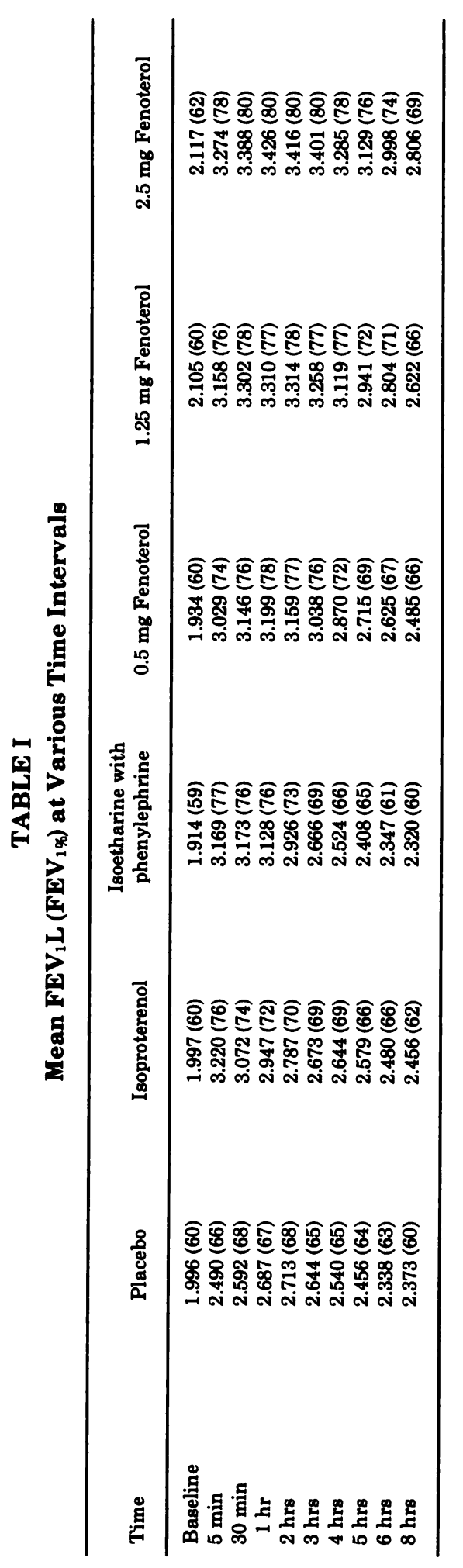

ment group, while the $0.5-\mathrm{mg}$ fenoterol treatment group was not different from either the 2.5-mg or the 1.25-mg fenoterol treatment group.

There was no significant change in blood pressure during testing. The mean systolic blood pressures ranged between 111.7 and $122.1 \mathrm{~mm} \mathrm{Hg}$, and the mean diastolic blood pressures ranged between 68.6 and $76.8 \mathrm{~mm}$ Hg.

Invariably, the mean pulse rate decreased with treatment, but the changes from baseline were not significant. The mean pulse ranged between 78.7 and 94.3 beats/min. The pulse rate increased and was greater than 100 beats/min following treatment in four cases with placebo (highest 120 beats/ min), in two cases with isoetharine with phenylephrine (highest 136 beats/min), in six cases with isoproterenol (highest 132 beats/min), in four cases with $0.5 \mathrm{mg}$ fenoterol (highest 126 beats/min), in two cases with $1.25 \mathrm{mg}$ fenoterol (highest 120 beats/ $\mathrm{min}$ ), and in three cases with $2.5 \mathrm{mg}$ fenoterol (highest 120 beats/min). With the exception of sinus tachycardia, the electrocardiograms were normal.

Table II summarizes the adverse experience with each treatment. The blood sugar, BUN, SGOT, total bilirubin, total protein, albumin, and urinalysis were normal at the beginning and end of testing, as was the CBC with differential, with the exception of the increased eosinophil count in 19 subjects.

\section{Discussion}

Fenoterol in studies with placebo controls has previously been found to be effective not only when delivered by a mask to asymptomatic asthmatic children studied for 1 hour, but also when delivered by metered dose inhaler to asthmatic adults with unspecified smoking histories studied for 8 hours. ${ }^{3}$ Two studies with placebo controls found fenoterol to have significant and prolonged bronchodilator effects when administered orally to six patients with 


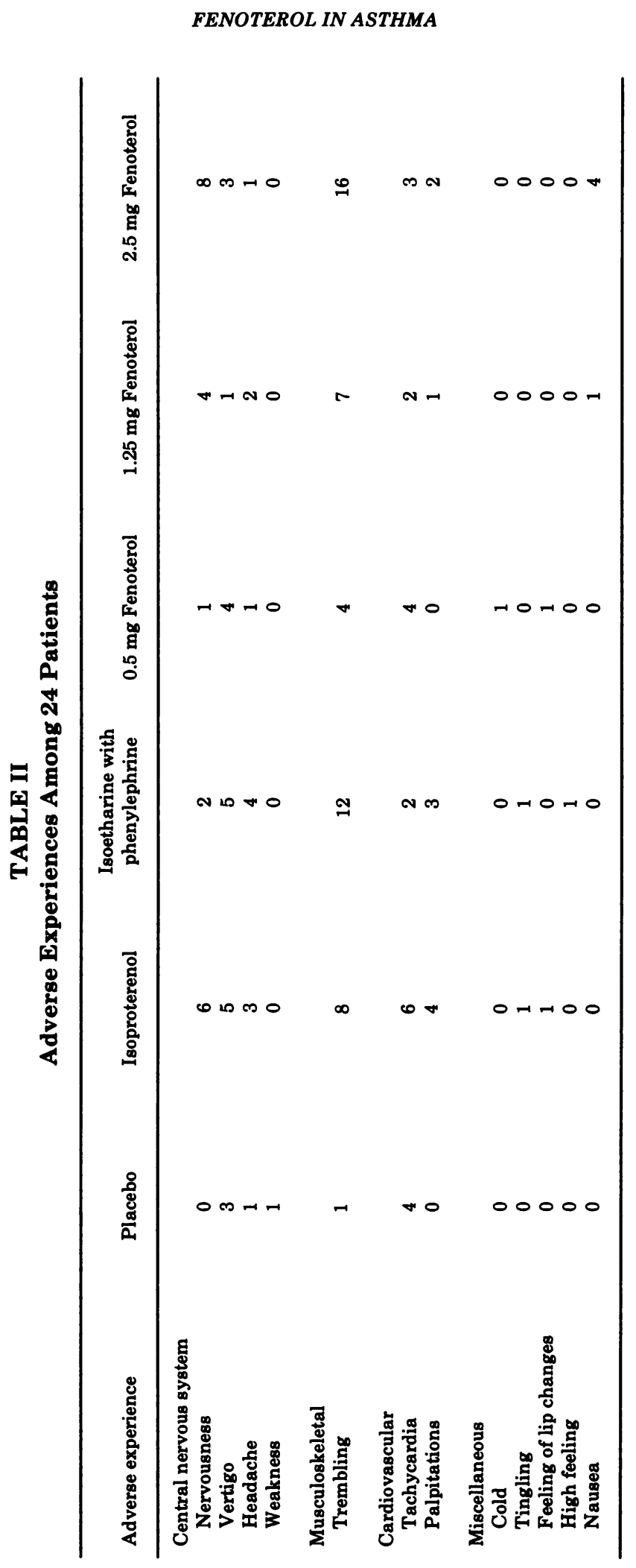

February-March 1983 
bronchial asthma and four with asthmatic bronchitis with or without emphysema, and when administered orally to five patients with asthma and 15 patients with combinations of asthma, bronchitis, and/ or emphysema with unspecified smoking histories.

In the present study, fenoterol, when administered with an intermittent positivepressure breathing device to nonsmoking young adult asthmatic subjects, produced significantimprovement in expiratory flows at each lung volume as measured by $\mathrm{FEV}_{1}$, FEF $_{25-75 \%}$ and FEF $_{25 \%}$ for 6 to 8 hours as shown in Figs. 1, 2, and 3. When compared to placebo, the highest fenoterol dose (2.5 $\mathrm{mg}$ ) had a longer effect on $\mathrm{FEV}_{1}$ and $\mathrm{FEF}_{25-75 \%}$ than the lowest fenoterol dose $(0.5 \mathrm{mg})$; but when both fenoterol doses were compared to each other, there was no difference. The duration of action of fenoterol was superior to both isoetharine with phenylephrine (2 hours) and isoproterenol (1 hour).

Previous studies have not investigated the effect of fenoterol on expiratory flows at low lung volumes. Figure 3 shows that fenoterol produces prolonged improvement in the forced expiratory flow at 25 per cent of vital capacity.

The importance of placebo controls is indicated by the improvement noted in the placebo treatment group in this study and others. ${ }^{1,3,4}$ In addition to the placebo effect, part of the improvement is probably related to the natural tendency toward improvement during the first wakeful hours ${ }^{5}$ and the subsequent relatively quiet test period. The experimental design of discontinuing testing in symptomatic subjects whose $\mathrm{FEV}_{1}$ had returned to baseline exaggerates placebo group improvement.

Adverse effects of treatment were least frequent with $0.5 \mathrm{mg}$ fenoterol; intermedi- ate in frequency with $1.25 \mathrm{mg}$ fenoterol, isoetharine with phenylephrine, and isoproterenol; and most frequent with $2.5 \mathrm{mg}$ fenoterol (Table II).

Fenoterol has thus been found to be an effective bronchodilator for treatment of asthma in young adult nonsmokers when delivered by IPPB with a duration of action of 6 to 8 hours. It has been shown to improve air flows at low lung volumes. Increasing the dosage of fenoterol from 0.5 $\mathrm{mg}$ to $2.5 \mathrm{mg}$ produced more side effects but did not improve bronchodilator activity.

\section{References}

1. Blackhall MI, Dauth M, Mahoney M, O'Donnell SR. Inhalation of fenoterol (Berotec) by asthmatic children. Med J Aust. 1976; 2:439-444.

2. Gemei AM, Miller WF, Miller J, Gast, LR. Bronchodilator effect of a new oral beta adrenergic stimulant, TH 1165a. Chest. 1976; 70:460-465.

3. Pennock BE, Rogers RM, Ryan BR, Ayers LN. Aerosol administration of fenoterol hydrobromide (Th 1165a) in subjects with reversible obstructive airway disease. Chest. 1977; 72: 731-766.

4. Steen SN, Smith R, Kuo J, Ziment I, Beall G. Comparison of bronchodilator effects of oral therapy with fenoterol hydrobromide and ephedrine. Chest. 1977; 72:291-295.

5. Soutar CA, Costello J, Ijaduola O, Turner-Warwidk M. Nocturnal and morning asthma: relationship to plasma corticosteroids and response to cortical infusion. Thorax. 1975; 30:436-440.

Reprint requests to: Dr. John G. Weg, Pulmonary Division, Box 055, University Hospital, S11306, Ann Arbor, Mich. 48109. 